\title{
The application of CRISPR/Cas9 in hairy roots to explore the functions of AhNFR1 and AhNFR5 genes during peanut nodulation
}

\author{
Hongmei Shu ${ }^{1,2}$, Ziliang Luo ${ }^{2}$, Ze Peng ${ }^{2}$ and Jianping Wang ${ }^{2^{*}}$ (D)
}

\begin{abstract}
Background: Peanut is an important legume crop growing worldwide. With the published allotetraploid genomes, further functional studies of the genes in peanut are very critical for crop improvement. CRISPR/Cas9 system is emerging as a robust tool for gene functional study and crop improvement, which haven't been extensively utilized in peanut yet. Peanut plant forms root nodules to fix nitrogen through a symbiotic relationship with rhizobia. In model legumes, the response of plants to rhizobia is initiated by Nod factor receptors (NFRs). However, information about the function of NFRs in peanut is still limited. In this study, we applied the CRISPR/Cas9 tool in peanut hairy root transformation system to explore the function of NFR genes.

Results: We firstly identified four AhNFR1 genes and two AhNFR5 genes in cultivated peanut (Tifrunner). The gene expression analysis showed that the two AhNFR1 and two AhNFR5 genes had high expression levels in nodulating (Nod+) line E5 compared with non-nodulating (Nod-) line E4 during the process of nodule formation, suggesting their roles in peanut nodulation. To further explore their functions in peanut nodulation, we applied CRISPR technology to create knock-out mutants of AhNFR1 and AhNFR5 genes using hairy root transformation system. The sequencing of these genes in transgenic hairy roots showed that the selected AhNFR1 and AhNFR5 genes were successfully edited by the CRISPR system, demonstrating its efficacy for targeted mutation in allotetraploid peanut. The mutants with editing in the two AhNFR5 genes showed Nod- phenotype, whereas mutants with editing in the two selected AhNFR1 genes could still form nodules after rhizobia inoculation.
\end{abstract}

Conclusions: This study showed that CRISPR-Cas9 could be used in peanut hairy root transformation system for peanut functional genomic studies, specifically on the gene function in roots. By using CRISPR-Cas9 targeting peanut AhNFR genes in hairy root transformation system, we validated the function of AhNFR5 genes in nodule formation in peanut.

Keywords: CRISPR/Cas9, Mutants, Nod factor receptor (NFR) genes, Nodulation, Peanut, Symbiosis

\footnotetext{
* Correspondence: wangjp@ufl.edu

${ }^{2}$ Agronomy Department, University of Florida, Gainesville, FL 32610, USA

Full list of author information is available at the end of the article
}

C C The Author(s). 2020 Open Access This article is licensed under a Creative Commons Attribution 4.0 International License, which permits use, sharing, adaptation, distribution and reproduction in any medium or format, as long as you give appropriate credit to the original author(s) and the source, provide a link to the Creative Commons licence, and indicate if changes were made. The images or other third party material in this article are included in the article's Creative Commons licence, unless indicated otherwise in a credit line to the material. If material is not included in the article's Creative Commons licence and your intended use is not permitted by statutory regulation or exceeds the permitted use, you will need to obtain permission directly from the copyright holder. To view a copy of this licence, visit http://creativecommons.org/licenses/by/4.0/ The Creative Commons Public Domain Dedication waiver (http://creativecommons.org/publicdomain/zero/1.0/) applies to the data made available in this article, unless otherwise stated in a credit line to the data. 


\section{Background}

Cultivated peanut (Arachis hypogaea L.) is a leguminous crop with great economic values mainly for oil and food production. Cultivated peanut is an allotetraploid with two sub-genomes, $\mathrm{A}$ and $\mathrm{B}$ (AABB genome, $2 n=4 \mathrm{x}=$ 40). The two sub-genomes were presumably derived from two diploid ancestral species $A$. duranensis and $A$. ipaensis [1]. The genomes of the two ancestral species and two cultivated peanut cultivars (Tifrunner and Shitouqi) were fully sequenced and publicly available [1-3]. These reference genomes greatly facilitate peanut molecular and genetic studies. To characterize genes' functions in peanut genome, engineered gene overexpression and RNA interference (RNAi) have been widely used [4-6]. However, the gene overexpression can cause side effects for the organism and the RNAi knockdown cannot eliminate the function of remaining proteins, hence limited their ability for gene function characterization. There is a need to update the arsenal of gene functional analysis for peanut genetic study.

The CRISPR/Cas9 (clustered regularly interspaced short palindromic repeats/CRISPR-associated protein 9) system has successfully demonstrated precise gene editing in many plant systems [7]. CRISPR/Cas-mediated gene knockout, replacement, and insertion provide simple and efficient approaches for gene functional studies, plant biology, and precision plant breeding [8, 9]. The application of CRISPR/Cas9 in plants empowered plant breeders to control the target genes, which provides a great resource for rapid crops improvement [8, 9]. It's believed that CRISPR/Cas has the potential to enhance global food security and sustainable agriculture. However, there is little knowledge of the application of CRIS $\mathrm{PR} / \mathrm{Cas} 9$ in peanut.

The nitrogen fixing root-nodule symbiosis in peanut and other legume plants allows them to grow well in soil without or lack of nitrogen fertilizer input and produce protein-rich seeds. Most legumes including model legumes establish root-nodule symbiosis through the "root hair" infection. The plant root exudates such as flavonoids specifically induce the transcription of nodulation genes (Nod, Nol, Noe) [10,11], which are involved in the synthesis of nodulation factors (Nod factors, NFs) in rhizobia. NFs are recognized by membrane lysin motif (LysM) receptor-like kinases (LYK/LYR) of host root epidermal cells, and subsequently stimulate the signal transduction in plant roots to facilitate the rhizobial infection through infection thread (IT) formation and nodule primordia formation [12, 13]. The peanut form nodules predominantly with NF-producing Bradyrhizobium strains, but NF mutant Bradyrhizobium was reported to induce nodules in peanut $[14,15]$. The mode of rhizobial invasion in peanut is known as the "crackentry" $[16,17]$, which is different from the "root hair" infection path. The rhizobia enter the root through the middle lamella between adjacent axillary hair cells and invade into the cortex intercellularly. The large basal cells infected by the rhizobia divide repeatedly to form determinate nodules.

The recognition of NF from compatible rhizobia is a crucial step for root nodule symbiosis. Two NF receptor $(N F R)$ genes or their orthologs were identified and characterized in several legumes with root hair infection [18-24]. These NFR genes were named NFR1 and NFR5 in L. japonicus, both encoding LysM-type serine/threonine receptor kinases [19]. The response of legumes to rhizobial infection is initiated by NFRs, and symbiotic receptor kinase (SYMRK) amplifies the NF-perceived signal [14] which activates downstream symbiotic signaling pathway to start the nodule morphogenesis $[14,25,26]$.

In peanut, two putative NFRs (AhNFR1 and AhNFP) were identified [27], which are the orthologs of LjNFR1 and LjNFR5, respectively. The predicted protein of AhNFP had similar molecular features to both soybean GmNFR5 $\alpha$ and GmNFR5 $\beta$ [27]. In soybean, overexpression of $G m N F R 5 \alpha, G m N F R 5 \beta$ and GmNFR $1 \alpha$ in Nodmutants could recover Nod+ phenotypes [22, 28], and overexpression of GmNFR1 $\alpha$ also increased the nodule number per plant. The NFR proteins encoded by these two genes in Lotus japonicus form a heteromeric receptor complex to initiate downstream signaling [29]. Our previous reports $[26,30]$ indicated that the peanut NFR5 ortholog may play a role in recognizing nod factors. However, Karmakar et al. [15] considered that the peanut orthologs of NFR1 and NFR5 might not be the key genes for symbiosis establishment, because the expression levels of lipochitooligosaccharide (LCO)-binding receptor gene (LYR3) and exopolysaccharide (EPS) receptor gene (EPR3) were much higher than that of the classical NFRs (NFR1 and NFR5) in peanut. In this study, we conducted hairy root mediated CRISPR knockout of peanut $A$ hNFR1 and AhNFR5 genes to characterize their functions in nodulation symbiosis. The results not only approved that CRISPR/Cas9 in coupled with hairy root transformation system is a rapid approach in characterizing gene functions in roots, but also improved our understanding of the NFR genes' function in peanut nodulation.

\section{Results}

Retrieving and comparing the gene sequences of AhNFR1s and AhNFR5s

Using the coding DNA sequences (CDS) of GmNFR1 (DQ219806) and GmNFR5 (NM_001354196) as queries, four $A h N F R 1$ genes (two on A sub-genome named $A h N$ FR1A1 and AhNFR1A2, two on B sub-genome named $A h N F R 1 B 1$ and AhNFR1B2) and two AhNFR5 genes 
(AhNFR5A on A sub-genome and AhNFR5B on B subgenome) were identified from the peanut genomes at PeanutBase (Table 1). The two AhNFR5 genes had no intron while the four AhNFR1 genes had multiple introns (Table 1). Among the four AhNFR1 genes, the length of AhNFR1A1 sequence was longer than the other three $A h N F R 1$ genes due to its additional number of introns and expanded exons. The DNA sequence homology between AhNFR5A and AhNFR5B was 98\%; the homology between AhNFR1A1 and AhNFR1B1 was 96\%; the homology between AhNFR1A2 and AhNFR1B2 was 99\% (Additional file 1: Fig. S1).

The functional structures of the six putative peanut NFR protein sequences were similar to those reported orthologs in other legumes [31, 32]. They had three extracellular LysM domains, typical CXC (Cysteine-any amino acid-Cysteine) motifs in the interspaces domains between LysM1-LysM2 and LysM2-LysM3 [27] (Fig. 1).

Phylogenetic analysis based on protein sequences (Fig. 2) showed that AhNFR5A and AhNFR5B were closely related to LjNFR5-1/2 and GmNFR5A; four AhNFR1 proteins are the orthologs of LjNFR1 and GmNFR1A.

\section{Investigating the expression patterns of AhNFR1s and AhNFR5s during rhizobial infection}

To investigate the temporal gene expression patterns of these genes in Nod- E4 and Nod+ E5 after rhizobia inoculation, quantitative real time-PCR (q-PCR) was conducted. The six genes had different expression patterns in roots of Nod- E4 and Nod+ E5 after rhizobia inoculation (Fig. 3). Among the six putative peanut $A h N F R$ genes, the expression level of the four AhNFR1 genes was not induced in Nod- E4 after rhizobia inoculation, but they were induced in Nod+ E5 after inoculation. Both AhNFR1A1 and AhNFR1B1 were induced in Nod+ E5, but only at $16 \mathrm{~h}$ after inoculation (HAI) for AhNFR1A1 and at 16 and 24 HAI for AhNFR1B1 (Fig. 3a and b). However, $A h N$ FR1A2 and AhNFR1B2 were significantly induced in Nod+ E5 at all time points tested including early and late infection stages. The results suggested that among the four AhNFR1 genes, AhNFR1A2 and AhNFR1B2 might play major roles in rhizobial infection and nodule organogenesis when comparing with AhNFR1A1 and AhNFR1B1, because their expression levels are much more significantly different between Nod- E4 and Nod+ E5 (Fig. 3c and d). The expressions of AhNFR5A and AhNFR5B were only induced in Nod- E4 at 72 and 144 HAI, but these two genes were induced in Nod+ E5 throughout the infection stages. The significantly high expression levels of the two AhNFR5 genes in Nod+ E5 suggesting they were related with rhizobial infection and nodule organogenesis (Fig. 3e and f).

In addition, the CDSs of AhNFR1A2, AhNFR1B2, AhNFR5A and AhNFR5B of Nod- E4 and Nod+ E5 were checked (data not shown). The sequence comparisons showed that the four genes were all identical between Nod- E4 and Nod+ E5, and they were also identical to the DNA sequences obtained in PeanutBase. The results indicated that none of the four $A h N F R$ genes were mutated in Nod- E4 line.

Therefore, two AhNFR1 genes (AhNFR1A2 and $A h N F R 1 B 2)$ and two AhNFR5 genes (AhNFR5A and $A h N F R 5 B$ ) were selected to study whether these genes are required for nodule formation in peanut using CRIS PR/Cas9 system.

\section{Target site selection and construction of the sgRNA: Cas9 expression vector}

Two single guide RNAs (sgRNAs) named NFR1AB1 and NFR1AB2 were designed to target both AhNFR1A2 and AhNFR1B2 genes, but at different sites. Accordingly, p201G/Cas9:NFR1AB1 + NFR1AB2 vector harboring the both sgRNAs (NFR1AB1 and NFR1AB2) were inserted into one plasmid p201G/Cas9 to target both AhNFR1A2 and AhNFR1B2 genes for knocking out (Table 2). For AhNFR5 genes, three sgRNAs were designed (Table 2). Among them, one sgRNA (NFR5B) was designed to target $A h N F R 5 B$ gene and the other two sgRNAs (NFR5AB1 and NFR5AB2) were designed to target both AhNFR5A and AhNFR5B genes at two different sites. Therefore, p201G/Cas9:NFR5AB1 + NFR5AB2 vector targeting both AhNFR5A and AhNFR5B genes and p201G/Cas9: NFR5B vector targeting only $A h N F R 5 B$ gene were constructed, separately (Table 2, Additional file 1: Fig. S2).

Table 1 The summary of AhNFR1 and AhNFR5 genes identified in peanut genome

\begin{tabular}{llllcc}
\hline Genes & Gene model name & Orthologous gene in A or B genome & Position in the genomes & CDS length (bp) & No. of introns \\
\hline AhNFR5A & Arahy.VID2UW & Aradu.AXP1M & Arahy.05:9587654 9,589,441 (+ strand) & 1788 & 0 \\
AhNFR5B & Arahy.A8RCAK & Araip.NL2P7 & Arahy.15:9907797 9,909,581 (+ strand) & 1785 & 0 \\
AhNFR1A1 & Arahy.63XNPZ & Aradu.P4UQH & Arahy.07:5753891 5,769,002 (- strand) & 5220 & 35 \\
AhNFR1B1 & Arahy.IVY8DS & Araip.YG8RE & Arahy.17:7510512 7,514,680 (- strand) & 1959 & 12 \\
AhNFR1A2 & Arahy.MX792F & Aradu.8UK90 & Arahy.04:1275786 1,283,663 (+ strand) & 1869 & 11 \\
AhNFR1B2 & Arahy.SA9NCH & Araip.8R7CF & Arahy.14:1845319 1,852,888 (+ strand) & 2130 & 11 \\
\hline
\end{tabular}




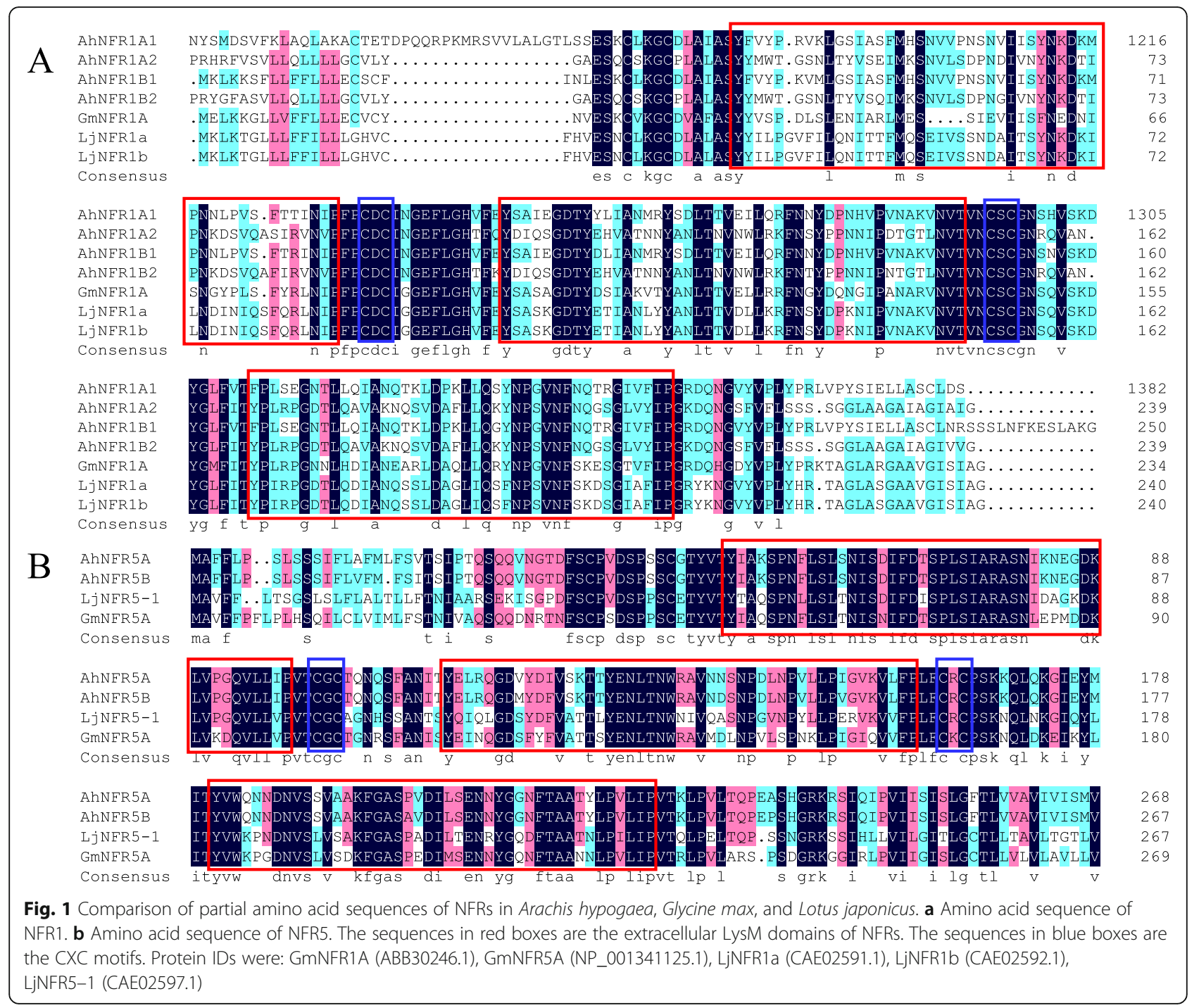

\section{Characterizing transgenic hairy roots AhNFR1 gene}

To validate the exogenous T-DNA insertion into transgenic hairy roots, only Green fluorescent protein (GFP) positive hairy roots, transformed with p201G/ Cas9:NFR1AB1 + NFR1AB2 vector, were subjected to sequencing validation. 12 independent AhNFR1 transgenic events showing GFP positive, named as $\mathrm{H} 1$ to H12. To evaluate the DNA editing on targeted AhNFR1 genomic regions, amplicons covering the two target sites (NFR1AB1 and NFR1AB2) were evaluated and further cloned and sequenced from the 12 hairy roots.

Amplicons from 7 out of 12 samples (H3, H4, H6, H8, H9, H11 and H12) had only one PCR band, with the same size ( $600 \mathrm{bp})$ as the wild type (WT). Whereas the rest five samples $(\mathrm{H} 1, \mathrm{H} 2, \mathrm{H} 5, \mathrm{H} 7, \mathrm{H} 10)$ had two PCR bands, and the sizes of them were around 300 and 600 bp (Additional file 1: Fig. S3). Based on our original design, the size of the expected main PCR product was $569 \mathrm{bp}$, and the designed cleavage length was about 300 bp. Thus, this result demonstrated that the precise cleavage events probably occurred in our designed genomic regions of AhNFR1 genes. To further validate whether the changed PCR size was derived from CRISPR/Cas9caused genomic truncation, we randomly picked 20 positive clones generated from each band of PCR products of each transgenic AhNFR1 peanut hairy root sample for Sanger sequencing.

The sequencing results of samples $\mathrm{H} 1, \mathrm{H} 2, \mathrm{H} 5, \mathrm{H} 7$ and $\mathrm{H} 10$ demonstrated that all 100 smaller sequences (20 clones for each sample) were truncated versions of AhNFR1 genomic sequences from NFR1AB1 DNA site to NFR1AB2 DNA site (Fig. 4). The cleavage DNA length was mostly -342 and -341 bp (Table 3). Thus, the CRISPR/Cas9 genome editing system succeeded in generating long DNA fragment deletions on the selected genomic region in peanut genomes. 


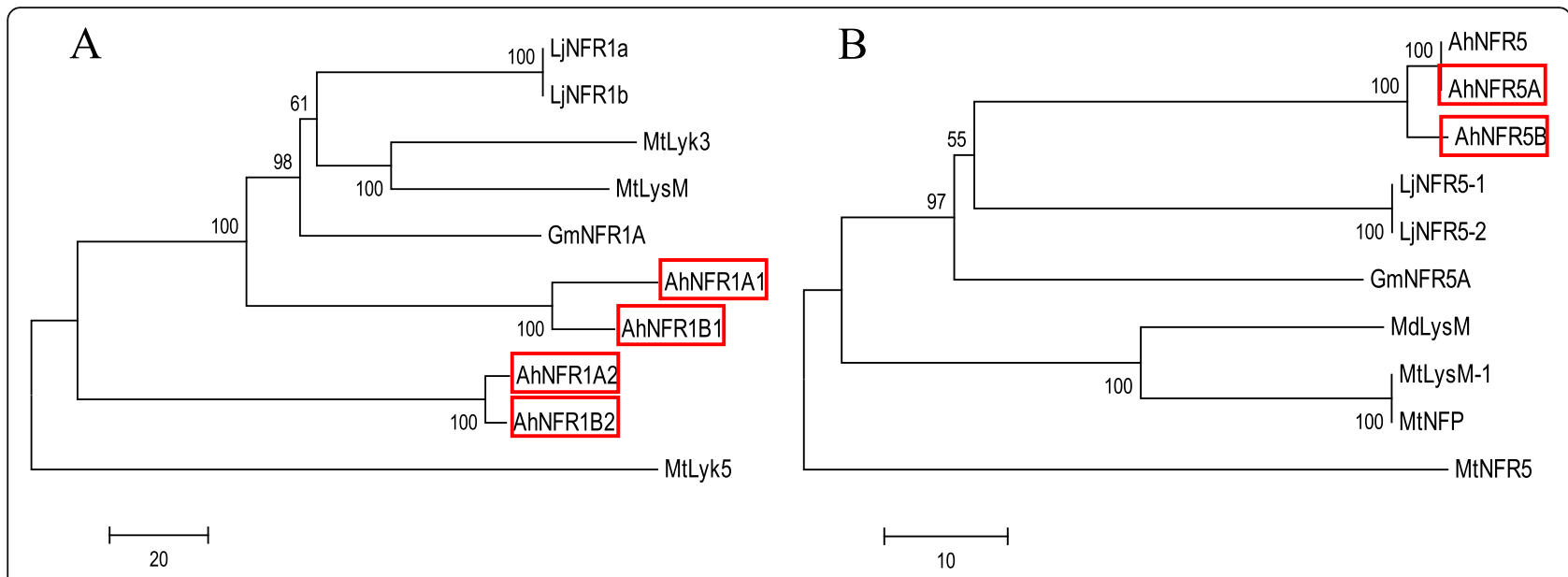

Fig. 2 The unrooted neighbor joining phylogenetic tree of NFRs in cultivated peanut and other legumes. a NFR1. b NFR5. The red boxes highlighted the NFRs orthologs we identified in PeanutBase. Other protein IDs were: AhNFR5 (ANS10208.1), GmNFR1A (ABB30246.1), GmNFR5A (NP_001341125.1), LjNFR1a (CAE02591.1), LjNFR1b (CAE02592.1), LjNFR5-1 (CAE02597.1), LjNFR5-2 (CAE02598.1), MdLysM (AEN71536.1), MtLyk3 (AAQ73159.1), MtLyk5 (CAN88846.1), MtLysM (CAN88845.1), MtLysM-1 (CAO02950.1), MtNFP (ABF50224.1), MtNFR5 (AET03984.1)
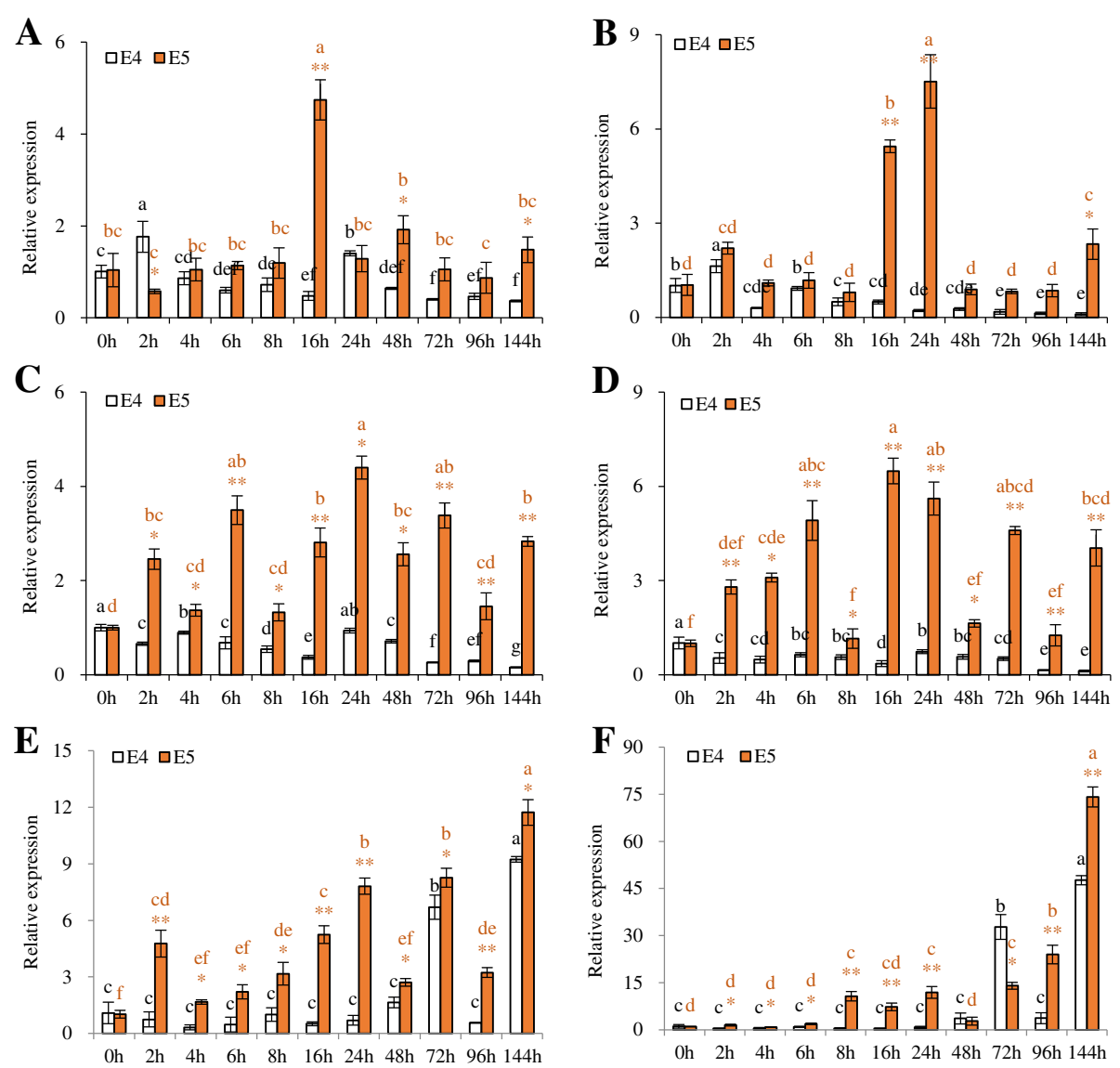

Fig. 3 Expression patterns of AhNFR genes in roots of Nod- E4 and Nod+ E5 inoculated with rhizobia Lb8. The time points included $0 \mathrm{~h}, 2 \mathrm{~h}, 4 \mathrm{~h}$, $6 \mathrm{~h}, 8 \mathrm{~h}, 16 \mathrm{~h}, 24 \mathrm{~h}, 48 \mathrm{~h}, 72 \mathrm{~h}, 96 \mathrm{~h}$ and $144 \mathrm{~h}$ for AhNFR1A1 (a), AhNFR1B1 (b), AhNFR1A2 (c), AhNFR1B2 (d), AhNFR5A (e), and AhNFR5B (f). Asterisks indicate significant differences between $\mathrm{E} 4$ and $\mathrm{E} 5$ as determined by student's t-test $\left({ }^{*}, p<0.05 ;{ }^{*}, p<0.01\right)$. Letters on columns indicate the significantly different $(p<0.05)$ groups within E4 (black letters) or within E5 (orange letters) after post-hoc comparison 
Table 2 Target sequences of sgRNAs designed in this study

\begin{tabular}{llll}
\hline sgRNAs & Target sequence (5'-3') & Targeted genes & Constructs (plasmid:sgRNAs) \\
\hline NFR1AB1 & TCTAGCTTCCTACTACATG & AhNFR1A2 and AhNFR1B2 & p201G/Cas9:NFR1AB1 + NFR1AB2 \\
NFR1AB2 & TTACCGTTAACTGCTCCTG & & p201G/Cas9:NFR5AB1 + NFR5AB2 \\
NFR5AB1 & GCAAGTAACATAAAGAATG & AhNFR5A and AhNFR5B & \\
NFR5AB2 & CTTGGGGGCACAGTTTACA & & p201G/Cas9:NFR5B \\
NFR5B & ACTCAACCCGAGCCTTCACA & AhNFR5B & \\
\hline
\end{tabular}

For the 12 samples with longer PCR product of 569 bp, 240 positive clones (20 clones for each sample's PCR product) were randomly picked for Sanger sequencing analyses. The results showed no modifications at the target genes in hairy roots $\mathrm{H} 11$ and $\mathrm{H} 12$ (data not shown). However, various types of nucleotide insertion and deletion mutations at target NFR1AB1 genomic sites were observed on the other 10 samples, and mostly -1 bp deletion at target NFR1AB2 genomic site (Fig. 5) (Additional file 1: Table S1). Except for sample H9, in the rest nine samples, examined target NFR1AB1 and NFR1AB2 genomic sites of some clones still kept unedited, the same as the wild type DNA sequence. The results suggested that among the genome knockout transgenic AhNFR1 events, mosaicism was observed in each transgenic event, which may disturb later phenotypic analysis [33]. The phenotyping of transgenic AhNFR1 hairy roots after rhizobia inoculation showed that all the positively transformed hairy roots with genome editing produced nodules except for samples $\mathrm{H} 4$ and H6. Therefore, we considered that the modification of AhNFR1A2 and AhNFR1B2 genes identified in this study did not affect the nodule formation.

\section{AhNFR5 gene}

To validate the exogenous T-DNA insertion in AhNFR5 transgenic hairy roots transformed with p201G/Cas9: NFR5AB1 + NFR5AB2 vector (targeting both AhNFR5A and $A h N F R 5 B$ genes), 10 independent transgenic events showing GFP positive, named as F1 to F10 were screened. To evaluate the DNA editing occurred at the targeting AhNFR5A and AhNFR5B genomic regions of

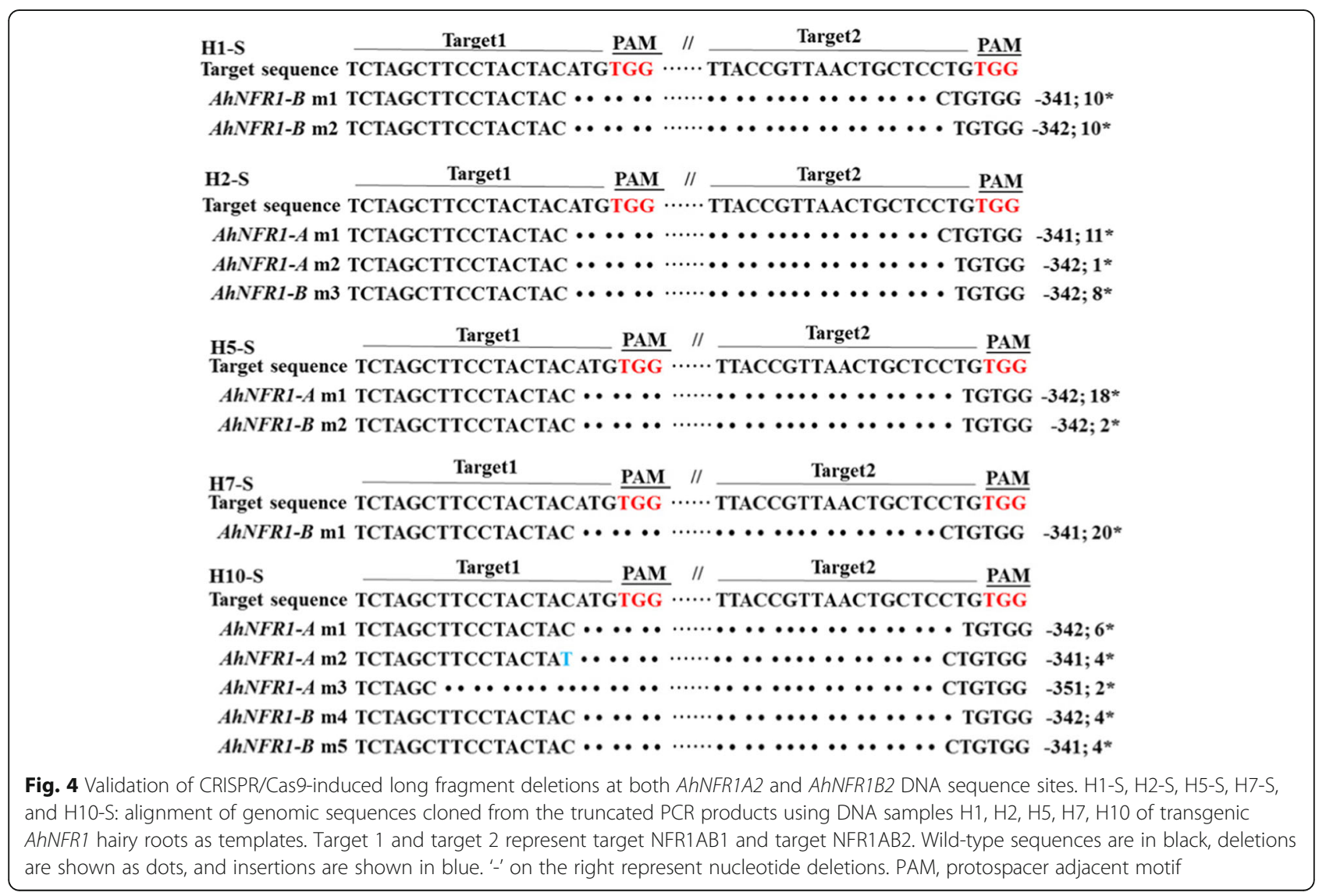


Table 3 Percentages of CRISPR/Cas9-caused AhNFR1 truncated events

\begin{tabular}{llll}
\hline Samples & Genes & \multicolumn{2}{l}{ Rate of different nucleotide deletion (\%) } \\
\cline { 3 - 4 } & & $-341 \mathrm{bp}$ & $-342 \mathrm{bp}$ \\
\hline $\mathrm{H} 1$ & AhNFR1A2 & 0 & 0 \\
& AhNFR1B2 & 50 & 50 \\
$\mathrm{H} 2$ & AhNFR1A2 & 92 & 8 \\
& AhNFR1B2 & 0 & 100 \\
$\mathrm{H} 5$ & AhNFR1A2 & 0 & 100 \\
& AhNFR1B2 & 0 & 100 \\
$\mathrm{H} 7$ & AhNFR1A2 & 0 & 0 \\
& AhNFR1B2 & 0 & 100 \\
$\mathrm{H} 10$ & AhNFR1A2 & 33 & 50 \\
& AhNFR1B2 & 50 & 50 \\
\hline
\end{tabular}

the 10 events, amplicons covering the two target sites (NFR5AB1 and NFR5AB2), were evaluated and further cloned and sequenced.

Except for sample F6, the PCR products in nine transgenic hairy roots had only one PCR band (Additional file 1: Fig. S4). We also selected 20 clones of the PCR product of each band for sequencing. The PCR products in hairy root $\mathrm{F} 6$ had two bands and the sequencing results showed that not only long sequence (736 bp) deletion but also 1 bp deletion at target NFR5AB1 site occurred (Fig. 6) (Additional file 1: Table S2). Among the 10 hairy roots, there were no modifications detected in AhNFR5 gene sequence from samples F7 and F10. In the other eight samples, the sequences of all clones of sample F1, F3, F6 and F9 at target NFR5AB1 or target NFR5AB2 site were edited, while some clones of other samples at the two target sites were not edited. Mosaicism was observed in the 8 transgenic $A h N F R 5$ events.

The sequence mutations on AhNFR5 hairy roots caused Nod- phenotype of sample F1, F3, F6 and F9 (Table 4). The sequencing and phenotype results indicated that when AhNFR5A and AhNFR5B genes' sequence of all clones from one transgenic $A h N F R 5$ event were all edited, no nodule could be formed. Therefore, we concluded that $A h N F R 5 A$ and $A h N F R 5 B$ genes were the key genes required for peanut nodule formation.

To validate the exogenous T-DNA insertion in $A h N F R 5 B$ transgenic hairy roots transformed with p201G/Cas9:NFR5B vector (targeting only $A h N F R 5 B$ gene), DNAs were extracted from 10 independent transgenic events. The PCR products of AhNFR5B in 10 transgenic hairy roots had only one PCR band (Additional file 1: Fig. S5). As shown in Table 5, 10 independent transgenic events of $A h N F R 5 B$ samples (5B1 5B10) were analyzed. The sequencing results showed that there was no modification detected in A sub-genome from the 10 hairy roots, indicating that there was no mismatched nucleotide with NFR5B-sgRNA. No sequence editing was detected in samples 5B1, 5B5, 5B6, 5B8 and 5B10. However, various types of nucleotide insertion and deletion mutations were detected in the rest five samples: 5B2, 5B3, 5B4, 5B7 and 5B9. The phenotype results of transgenic $A$ hNFR5B hairy roots (Fig. 7) showed that samples 5B2, 5B3, 5B4, 5B7 and 5B9 had no nodule, but other unedited hairy roots had nodules. Among the five no-nodule hairy roots, $A$ hNFR5B genes' sequence of all clones from samples 5B2, 5B3, and 5B9 were all edited, but $A h N F R 5 B$ genes' sequences of all clones from samples $5 \mathrm{~B} 4$ and $5 \mathrm{~B} 7$ were partly edited. Combining the results of AhNFR5 transgenic hairy roots transformed with p201G/Cas9: NFR5AB1 + NFR5AB2 vector, these results showed that $A h N F R 5 B$ genes' sequence of all clones from one transgenic event were all edited, which could cause non-nodulation phenotype. However, if $A h N F R 5 B$ genes' sequence of clones from one transgenic event were partly edited, the phenotype remained uncertain.

\section{Discussion \\ CRISPR system}

Peanut is an important economic crop. With the achievements in peanut genome researches and whole genome-wide gene identification studies, the peanut community urgently needs a highly efficient and costeffective CRISPR/Cas9 system for gene function studies. To establish the CRISPR system for root-related studies in peanut, the p201G/Cas9 vector, which showed high editing efficiency in soybean [34], was selected for this study. To examine the qualification for effective CRIS PR/Cas9 genomic editing in allotetraploid peanut genome, two sgRNAs (NFR1AB1 and NFR1AB2) for $A h N$ FR1A2 and AhNFR1B2 and two sgRNAs (NFR5AB1 and NFR5AB2) for AhNFR5A and AhNFR5B designed in identical genomic regions between the homologous copies at A sub-genome and B sub-genome, were employed to examine the efficiency of this genome editing system in allotetraploid peanut. The various type of editing results of both targeted genes indicated that p201G/Cas9 CRISPR vector had high editing efficiency, since the long genomic fragment deletions required high Cas9-sgRNAcomplex activity to ensure the two designed cleavage sites be effectively recognized and cleaved simultaneously [35, 36].

A single specific sgRNA (NFR5B) was designed for $A h N F R 5 B$ gene. The sequencing results showed that $A h N F R 5 B$ gene was edited in $50 \%$ of GFP-positive transgenic $A$ hNFR5B hairy roots. However, AhNFR5A and $A h N F R 5 B$ genes were edited in $80 \%$ of transgenic AhNFR5 hairy roots with two sgRNAs (NFR5AB1 and NFR5AB2) targeting both AhNFR5A and AhNFR5B genes. This result suggested that the editing efficiency of one sgRNA in CRISPR vector was lower than that of 


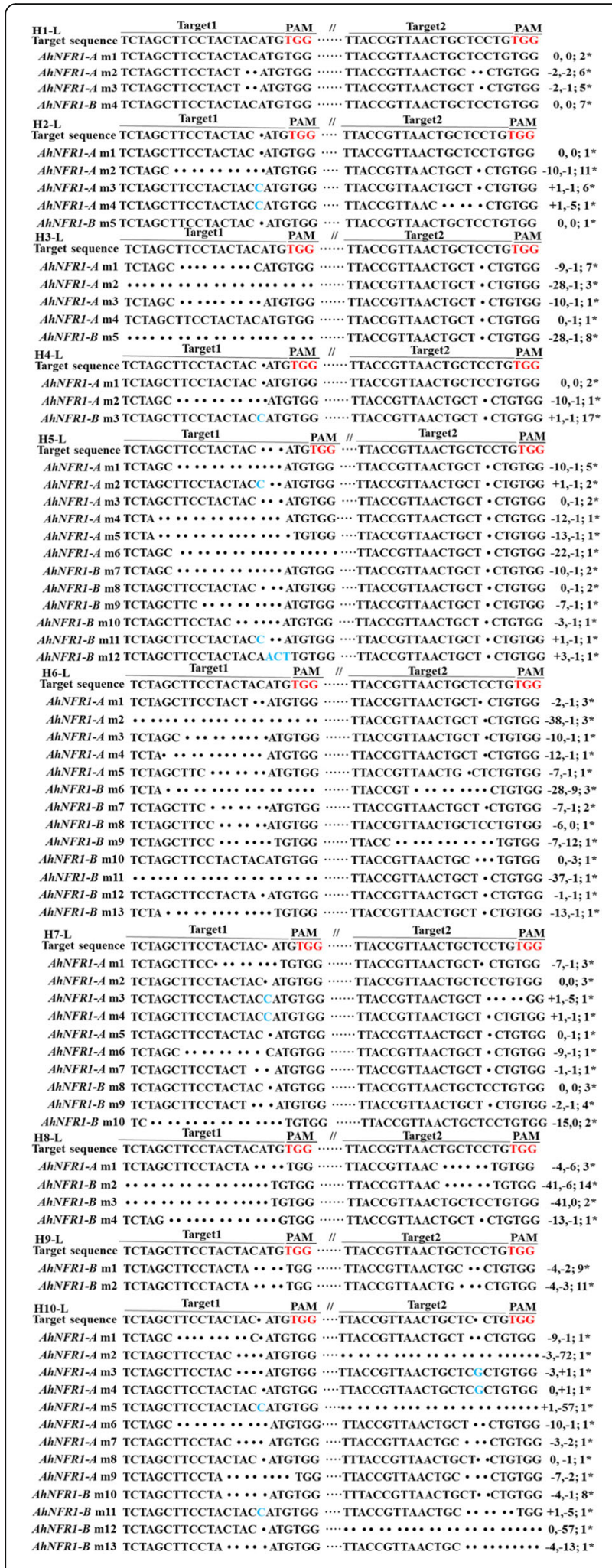

Fig. 5 Validation of CRISPR/Cas9-induced mutations at both AhNFR1A2 and AhNFR1B2 DNA sequence sites. H1-L H10-L: alignment of genomic sequences cloned from the long PCR products using DNA samples $\mathrm{H} 1 \sim \mathrm{H} 10$ of transgenic AhNFR1 hairy roots as templates. Target 1 and target 2 represent target NFR1AB1 and target NFR1AB2. Wild-type sequences are in black, deletions are shown as dots, and insertions are shown in blue. ' -1, ' + ' and ' 0 ' on the right represent nucleotide deletions, insertions and no mutation, respectively

two sgRNAs. In another word, two or more sgRNAs in one CRISPR vector could increase the gene editing efficiency.

In summary, our study provided a successful example of using CRISPR/Cas9 system for highly efficient genome editing in allotetraploid peanut, which can be widely applied to generate mutations for other functional genomics studies or crop improvement in peanut.

A. rhizogenes mediated hairy root production has been utilized as a powerful tool in peanut to discover gene function and study root biology [5, 6, 37]. It is a highly efficient technique for generating composite plants composed of transgenic roots and wild-type shoot. In this study we constructed the CRISPR/Cas9 system in hairy roots to explore gene function during nodule formation. However, the hairy root transformation system may have its limitations to study gene functions by CRISPR/Cas9 technology. Particularly, mosaicism was observed in each transgenic event, which might disturb later phenotypic analysis. Mosaic mutations are a major challenge of CRISPR/Cas9 editing system [38]. Previous research [33] inferred that mosaicism could be eliminated during the later stage of selection. However, hairy root transformation system could not generate offspring. Due to the possible mosaicism, hairy root transformants from CRIS PR-Cas9 experiment would generate Nod-, Nod+ or Nod-/Nod+ sectors. Therefore, in the current study, the clear Nod- phenotype observed from the knockout events (Fig. 7) provided us certain confidence in the knockout experiments. Future improvement of this gene editing system can be achieved by applying the stable embryogenesis transformation systems.

\section{The functions of AhNFR genes during nodule formation}

In a common symbiotic signaling pathway characterized in model legume species, the first step is the recognition of NFs by LYK. There are two forms of such kinases, NFR1 (or LYK3 in M. truncatula) and NFR5 (or NFP in M. truncatula) [20, 24, 39]. In previous researches [27], peanut NFR1 was found to have incomplete LysM receptor-kinase domains. Moreover, the transcriptome of Nod- E4 and Nod+ E5 showed that NFR1 was not a differentially expressed gene in any genotypes [26]. In this study, four putative AhNFR1 genes (AhNFR1A1, 


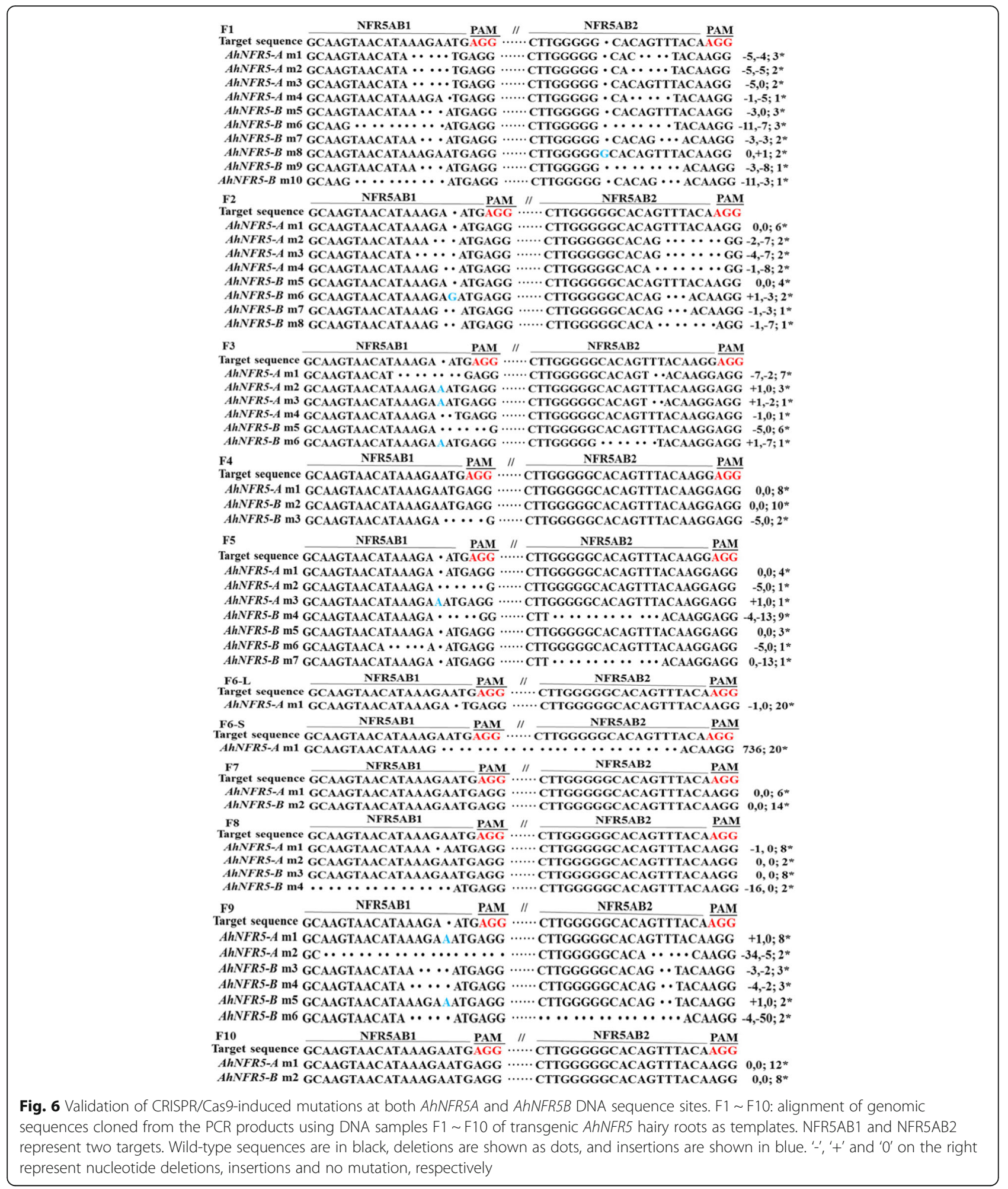

AhNFR1B1, AhNFR1A2 and AhNFR1B2) were identified in the peanut genome. The high homology of DNA sequences between AhNFR1A1 and AhNFR1B1, and between $A h N F R 1 A 2$ and $A h N F R 1 B 2$ indicated that these genes might have similar functions. However, the sequence length of AhNFR1A1 is longer than others, with two additional domains (STKc IRAK and PKc like superfamily) annotated in PeanutBase. A different $A h N$ FR1A1 gene structure (gene symbol: LOC112702229) was annotated in the NCBI database, which was shorter 
Table 4 Mutation genotype and nodulation phenotype of independent AhNFR5-edited hairy root

\begin{tabular}{|c|c|c|c|c|c|c|}
\hline \multirow[t]{2}{*}{ Samples } & \multicolumn{2}{|c|}{ Mutation at target $5 \mathrm{AB} 1$ site } & \multicolumn{2}{|c|}{ Mutation at target $5 \mathrm{AB} 2$ site } & \multirow{2}{*}{$\begin{array}{l}\text { GFP } \\
\text { positivity }\end{array}$} & \multirow{2}{*}{$\begin{array}{l}\text { Nodule } \\
\text { phenotype }\end{array}$} \\
\hline & $\overline{\mathrm{At}}$ & $\mathrm{Bt}$ & $\overline{\text { At }}$ & $\mathrm{Bt}$ & & \\
\hline F1 & $-5,-1$ & $-3,-11$ & $-4,-5, n$ & $-3,-7,-8,+1$ & + & - \\
\hline $\mathrm{F} 2$ & $n,-2,-4,-1$ & $n,-1,+1$ & $n,-7,-8$ & $n,-3,-7$ & + & + \\
\hline F3 & $-7,+1,-1$ & $-5,+1$ & $-2, n$ & $n,-7$ & + & - \\
\hline $\mathrm{F} 4$ & $n$ & $n,-5$ & $\mathrm{n}$ & $n$ & + & + \\
\hline F5 & $n,-5,+1$ & $n,-4,-5$ & $\mathrm{n}$ & $n,-13$ & + & + \\
\hline F6 & $-1,-736$ & / & $n,-736$ & / & + & - \\
\hline F7 & $n$ & $\mathrm{n}$ & $\mathrm{n}$ & $n$ & + & + \\
\hline F8 & $n,-1$ & $n,-16$ & $\mathrm{n}$ & $n$ & + & + \\
\hline F9 & $+1,-34$ & $-3,-4,+1$ & $-5, n$ & $-2, n,-50$ & + & - \\
\hline F10 & $\mathrm{n}$ & $\mathrm{n}$ & $\mathrm{n}$ & $\mathrm{n}$ & + & + \\
\hline
\end{tabular}

'At' represents target sequence in AhNFR5A gene; 'Bt' represents target sequence in AhNFR5B gene. ' -1 , ' + ' and ' $n$ ' in the left four columns represent nucleotide deletions, insertions and no mutation respectively. ' - ' and ' + ' in the right two columns represent negative and positive

in sequence length. To keep the gene model consistent with Legume Information System, we used the gene information from PeanutBase in this study.

Among the four identified AhNFR1 genes, AhNFR1A2 and $A h N F R 1 B 2$ might be related to nodule formation since they were induced in Nod+ E5 but not in Nod- E4 after rhizobial infection. However, all 10 knockout events of AhNFR1A2 and AhNFR1B2 genes, produced nodules except two lines, which indicated that $A h N$ FR1A2 and AhNFR1B2 may not be an absolutely required gene for nodule formation. Most likely, other NFR1 paralogs complemented the function of tested NFR1 copy for nodulation in peanut. AhNFR1 genes were relatively divergent with many copies. Using the soybean NFR1 gene sequence as a query, we blasted the peanut genomes and identified four copies with very stringent homology criteria. However, when we relaxed the criteria, many more NFR1 like genes could be identified in peanut genomes. For example, when the $E$ value was set at $e^{-10}, 35$ NFR1 like genes can be identified. To identify which NFR1 genes play roles in peanut nodule formation out of a large number of candidates is a big task. So, in this study we selected $A h N F R 1 A 2$ and $A h N F R 1 B 2$ genes for the knockout experiment. Further research should be conducted to validate the function of different copies of NFR1 gene in peanut nodulation. An RNAi experiment could be a more valuable method to down-regulate all the paralogs efficiently in hairy roots than CRISPR/Cas9.

The LysM domain of NFR5 at least partially determines the specificity of NF recognition [26, 40]. NFR5 had been reported to be coupling with NFR1 as heterodimers in NF recognition signal transduction [29]. One NFR5 ortholog (AhNFP) was identified in peanut genome with complete LysM receptor-kinase domains by Ibanez et al. [27]. In this study, two AhNFR5 genes were identified with the same extracellular domain. DNA sequences of the two AhNFR5 genes were the same between Nod- E4 and Nod+ E5 indicating that the different nodulation phenotypes between the sister recombinant inbred lines [26], E4 and E5, were not caused by mutation of AhNFR5 genes. However, since AhNFR5 gene was induced in Nod- E4, most likely the genes responsible for the different nodulation phenotypes between E4 and E5 are downstream of AhNFR5 gene. Araip.NL2P7, one NFR5 ortholog in diploid peanut (Arachis ipaensis), was identified as a differentially expressed gene (DEG) [26], which was up-regulated in Nod+ genotype in response to rhizobia inoculation, indicating the induction of its expression during the nodulation process. Here, the two AhNFR5 genes had high expression levels in Nod+ genotype (E5) compared with Nod-genotype (E4), and also when both AhNFR5A and $A h N F R 5 B$ were mutated in transgenic hairy roots, no nodule was formed. Therefore, we believe AhNFR5 genes, either $A h N F R 5 A$, or $A h N F R 5 B$, or both are required for peanut nodule formation. Since it was confirmed that the lines with only $A h N F R 5 B$ mutated had no nodule formation, at least $A h N F R 5 B$ was required for peanut nodule formation. Whether $A h N F R 5 A$ is required for nodule formation needs to be further explored. Similarly, in soybean, the mutants of either of the two NFR5 genes showed Nod-phenotypes [22].

\section{Conclusions}

The CRISPR/Cas9 in coupled with hairy root transformation system was established in peanut to study gene functions during nodule formation. The nodulation phenotype of mutants with editing in AhNFR1 genes (AhNFR1A2 and AhNFR1B2 identified in this study) could still form nodules after rhizobia inoculation, whereas mutants with editing in AhNFR5 genes 
Table 5 Sequence analyses of CRISPR/Cas9-induced mutations at AhNFR5B DNA sequence site of transgenic AhNFR5B hairy roots

\begin{tabular}{|c|c|c|c|c|}
\hline Samples & & Sequences & $\%$ & $\Delta$ \\
\hline \multirow[t]{2}{*}{ Target5B } & A & ACTCAACCCGAGGCTTCACATGG & & \\
\hline & $\mathrm{B}$ & ACTCAACCCGAGCCTTCACATGG & & \\
\hline \multirow[t]{2}{*}{$5 \mathrm{~B} 1$} & A & ACTCAACCCGAGGCTTCACATGG & 100 & WT \\
\hline & $\mathrm{B}$ & ACTCAACCCGAGCCTTCACATGG & 100 & WT \\
\hline \multirow[t]{3}{*}{$5 \mathrm{~B} 2$} & A & ACTCAACCCGAGGCTTCACATGG & 100 & WT \\
\hline & $\mathrm{B}$ & ACTCAACCCGAGC - - - ACATGG & 60 & -4 \\
\hline & & ACTCAACCCGAGC - - CACATGG & 40 & -3 \\
\hline \multirow[t]{3}{*}{$5 \mathrm{~B} 3$} & A & ACTCAACCCGAGGCTTCACATGG & 100 & WT \\
\hline & $\mathrm{B}$ & ACTCAACCCGAGC - - - ACATGG & 60 & -4 \\
\hline & & ACTCAACCCGAGC - - CACATGG & 40 & -3 \\
\hline \multirow[t]{4}{*}{$5 \mathrm{~B} 4$} & A & ACTCAACCCGAGGCTTCACATGG & 100 & WT \\
\hline & $\mathrm{B}$ & ACTCAACCCGAGCCTTCACATGG & 40 & WT \\
\hline & & ACTCAACCCGA - - - - - ACATGG & 40 & -6 \\
\hline & & ACTCAACCCGAGCCTTCAACATGG & 20 & +1 \\
\hline \multirow[t]{2}{*}{$5 \mathrm{~B} 5$} & A & ACTCAACCCGAGGCTTCACATGG & 100 & WT \\
\hline & $\mathrm{B}$ & ACTCAACCCGAGCCTTCACATGG & 100 & WT \\
\hline \multirow[t]{2}{*}{$5 \mathrm{~B} 6$} & A & ACTCAACCCGAGGCTTCACATGG & 100 & WT \\
\hline & $\mathrm{B}$ & ACTCAACCCGAGCCTTCACATGG & 100 & WT \\
\hline \multirow[t]{4}{*}{$5 \mathrm{~B} 7$} & A & ACTCAACCCGAGGCTTCACATGG & 100 & WT \\
\hline & $\mathrm{B}$ & ACTCAACCCGAGCCTTCACATGG & 33.3 & WT \\
\hline & & ACTCAACCCGAGCCTTCAACATGG & 33.3 & +1 \\
\hline & & ACTCAACCCGAGC - - - CACATGG & 16.7 & -3 \\
\hline \multirow[t]{2}{*}{ 5B8 } & A & ACTCAACCCGAGGCTTCACATGG & 100 & WT \\
\hline & $\mathrm{B}$ & ACTCAACCCGAGCCTTCACATGG & 100 & WT \\
\hline \multirow[t]{2}{*}{$5 \mathrm{~B} 9$} & A & ACTCAACCCGAGGCTTCACATGG & 100 & WT \\
\hline & $\mathrm{B}$ & ACTCAACCCGAGC - - CACATGG & 100 & -3 \\
\hline \multirow[t]{2}{*}{$5 \mathrm{~B} 10$} & A & ACTCAACCCGAGGCTTCACATGG & 100 & WT \\
\hline & $\mathrm{B}$ & ACTCAACCCGAGCCTTCACATGG & 100 & WT \\
\hline
\end{tabular}

Sequence confirmation of nucleotide deletion and insertion mutations in peanut transgenic AhNFR5B samples. 'WT' represents wild type. Wild-type sequences are in black, difference between alleles is in blue, deletions are shown as dashes, and insertions are shown in red. Percentages next to sequences indicate the number of clones with sequence over the number of total clones sequenced. $\Delta$ is the base difference comparing with WT.

(AhNFR5A and AhNFR5B identified in this study) showed Nod- phenotype. Yet, mosaic editing patterns detected for both genes may hinder the interpretation of their functions. These results showed that CRIPR/Cas9 system worked in allotetraploid peanut hairy roots can be used for preliminary genes screening. A stable embryogenic transformation CRISPR system should be applied to further confirm the genes' function in the future.

\section{Methods}

\section{Plant materials}

Peanut cultivar 'Tifrunner' provided by Dr. Baozhu Guo at USDA-ARS (Tifton, GA) and a pair of peanut sister recombinant inbred lines (RILs), a non-nodulating (Nod-) 'E4'and a nodulating (Nod+) 'E5' [26, 30] were used in this study. The growth condition of all the plants used in this study was 16 -h-day $27^{\circ} \mathrm{C} / 8$-h-night $25^{\circ} \mathrm{C}$ cycle in growth chambers at University of Florida. 

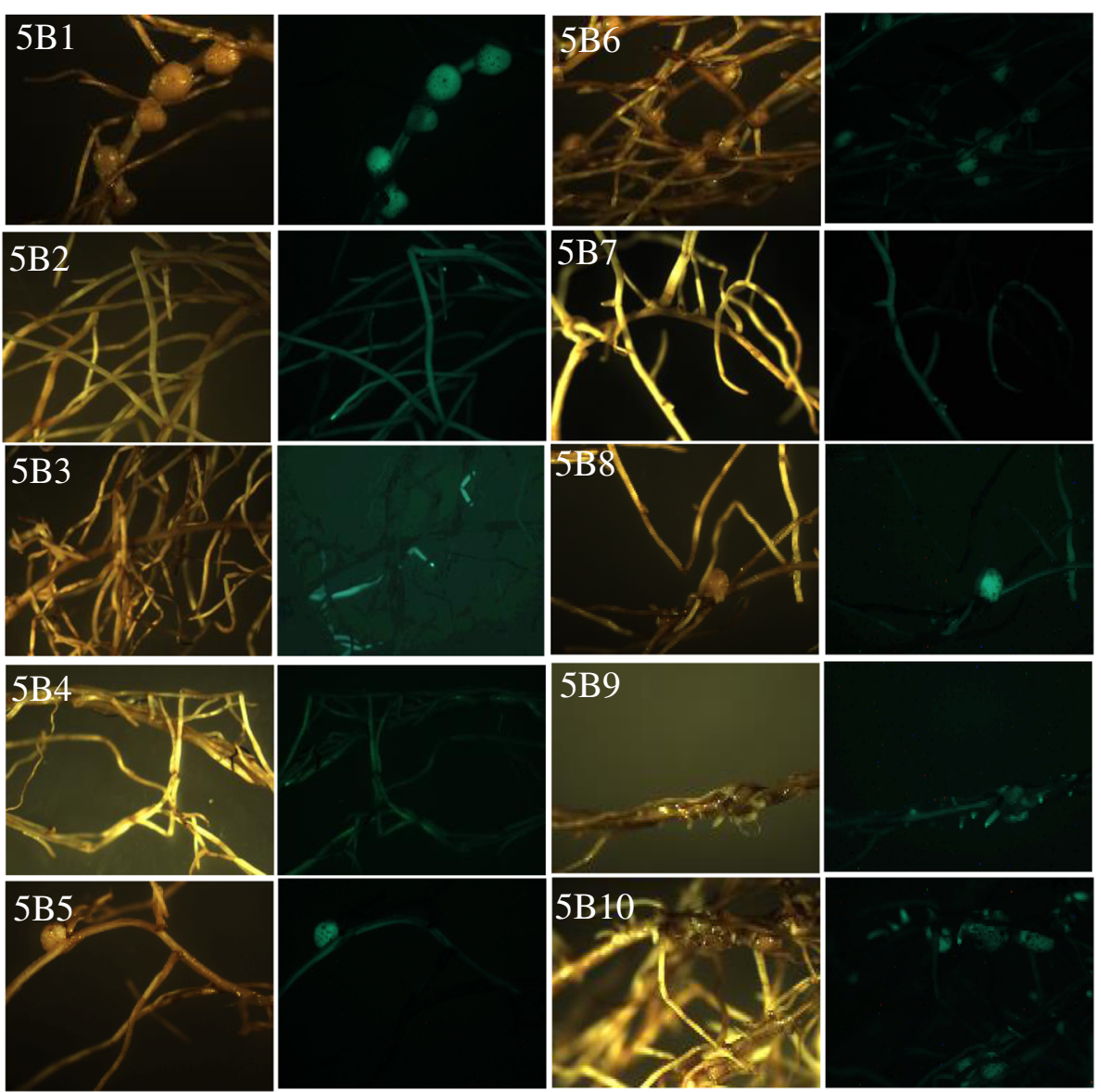

Fig. 7 Nodulation phenotypes of transgenic AhNFR5B hairy roots. 5B1 5B10 are ten independent events. The left images were hairy root under white light, and the right images were hairy roots under fluorescence light

For gene expression analysis, approximately 200 seeds of each genotype were sterilized in $0.1 \% \mathrm{HgCl}_{2}$ solution for seven minutes and then washed three times using sterilized $\mathrm{ddH}_{2} \mathrm{O}$ for five minutes each time. Seed germination and the rhizobia inoculation on peanut roots followed the method described by Peng et al. [26]. In brief, sterilized seeds were soaked in distilled water for 2 days, and then transferred into a germination box. After 4 days, germinated seeds were transferred to Ziploc bags with germination paper inserts containing $40 \mathrm{ml}$ $25 \%$ Hoagland's solution without N. A Bradyrhizobium spp. strain named Lb8 isolated from peanut nodules who had a high nodulation efficiency [41] was used for inoculum preparation. One $\mathrm{ml}$ of Lb8 $\left(\mathrm{A}_{600}=0.05-0.1\right)$ suspension was applied to roots when they were $6-7 \mathrm{~cm}$ long. For each genotype, a total of 100 plants were inoculated with the Lb8. At $0,2,4,6,8,16,24,48,72,96$ and $144 \mathrm{~h}$ after inoculation (HAI), the middle $2-3 \mathrm{~cm}$ of the primary root was cut from treated plants and immediately put into liquid nitrogen for RNA extraction. The middle $2-3 \mathrm{~cm}$ of the peanut primary root at 6 days after germination harbors the active rhizobial infection sites, where the lateral roots are about to emerge $[16,17]$.

\section{Identification and characterization of AhNFR genes}

To identify the genomic DNA sequences of AhNFR1 and AhNFR5 orthologs in peanut genomes, BLAST searches were performed by using the CDS of GmNFR1 (DQ219806) and GmNFR5 (NM_001354196) genes as queries against PeanutBase (https://peanutbase.org/) at Evalue $=0$. Domain search of AhNFR protein was performed by SWISS-MODEL homology modeling programs [42]. Phylogenetic analysis was conducted using MEGA 5 software [43]. Based on the CDS of the gene model from BLAST, we designed primers (Additional file 1: Table S3) to amplify them from the two genotypes, Nod- E4 and Nod+ E5, to obtain their cDNA sequences.

RNA samples were prepared from three biological replicates of both E4 and E5 at each time point after inoculation as described above. Total RNA was isolated using the Direct-zol RNA Miniprep Kit according to the manufacturer's protocol (Zymo Research, USA). First strand 
cDNA synthesis was carried out using a high capacity RNA-to-cDNA Kit (Applied Biosystems, USA). Due to the high similarity between the DNA sequences of homoeologous copies, primers for q-PCR were carefully designed from the diverged sequence regions between the homoeologous copies to amplify homoeologous gene-specific copy. Primers' (Additional file 1: Table S4) amplification efficiency (E) was estimated by running qPCR of a serial of diluted cDNA samples (E4 at $0 \mathrm{HAI}$ ). The standard curve was constructed by plotting the log of the starting quantity of template against the $\mathrm{Ct}$ value obtained during amplification of each dilution. The $\mathrm{E}$ values were calculated from the slope of the standard curve using the following formula: $E=10^{-1 / \text { slope }}$. Only the primers with $E$ value in a range of $90-105 \%$ were used for q-PCR. q-PCR was performed with three biological replicates and three technical replicates for each sample using the Power SYBR Green PCR Master Mix kit (Applied Biosystems, USA) and CFX96 Real-Time PCR Detection System (Bio-Rad, USA). Results obtained from the different treatments were standardized to the AhUbiquitin 2 [44], an internal control for peanut qPCR. Relative gene expression was calculated using the $2^{-\Delta \Delta \mathrm{Ct}}$ method [45]. Melting curves were recorded after cycle 40 by heating from 55 to $95^{\circ} \mathrm{C}$. Statistical analysis of the gene expression level among different time points or between the two varieties was performed by applying one-way analysis of variance (ANOVA). Probability values of less than 0.05 were considered significant, and an asterisk or letter identifies such significance in Fig. 3.

\section{sgRNA design and construction of sgRNA: Cas9 expression vector}

p201G/Cas9 plasmid (\#59178) and pUC-gRNA shuttle plasmid (\#47024) were ordered from Addgene (http://www. addgene.org/). The sgRNA cassette in pUC-gRNA was induced through the MtU6 promoter. Cas9 and GFP in p201G/Cas9 separately were driven by an enhanced cauliflower mosaic virus (CaMV) $35 \mathrm{~S}$ promoter. GFP was used as a visible marker to rapidly screen transgenic events.

The sgRNAs in the constructed vectors were designed by using the web-based tool CRISPR-P (http://cbi.hzau. edu.cn/crispr/) [46], which highlighted all potential CRIS PR sgRNA sequences (19bp or $20 \mathrm{bp}$ ) immediately followed by $5^{\prime}$-NGG (PAM) in the forward or reverse strands of the AhNFR CDS. For each target locus we chose, DNA oligos were synthesized from Invitrogen (Carlsbad, USA). DNA oligos were inserted between mtU6 promotor and sgRNA scaffolds by using overlapping PCR. The overlapping PCR products were ligated into p201G/Cas9 plasmid vector which was digested by restriction enzymes ApaI and SpeI [34]. The constructs (p201G/Cas9: sgRNAs) were first transformed into $E$. coli TOP10. The PCR (Additional file 1: Table S5) positive clones of the constructs were purified using Plasmid Kit (NEB, England). After Sanger sequencing of the constructs at the cloning site, the successfully constructed plasmid was then selected and used to transform Agrobacterium rhizogenes strain K599.

\section{Peanut hairy root transformation}

Hairy root transformation system using the A. rhizogenes strain K599 was described previously [47]. Briefly, in this study, K599 carrying the CRISPR/Cas9 plasmids of interest was grown on yeast mannitol plate supplemented with $50 \mu \mathrm{g} / \mathrm{ml} \mathrm{kanamycin}$ (Sigma, USA) for 2 days. Tifrunner peanut seedlings at 7 days after germination (DAG) were injected with K599 at the hypocotyl. Each GFP positive hairy root is an independent transgenic event because every hairy root develops independently after k599 injection for hairy root induction. After being injected, the peanut seedlings were transferred into pots filled with vermiculite and grown in the growth chamber (16-h-day $27^{\circ} \mathrm{C} / 8$-h-night $25^{\circ} \mathrm{C}$ cycle).

\section{GFP examination, genomic DNA extraction and mutation analyses}

Four weeks after transformation, the transformed peanut plants were dug out and observed under a stereomicroscope (Olympus, Japan). The plant seedlings with GFP positive hairy roots were replanted into vermiculite for recovery and then were inoculated by rhizobia strain Lb8 [26]. At 1 month after rhizobia inoculation, nodulation phenotype was observed. The DNA of GFP positive hairy roots were extracted using the CTAB method as previously described [48]. The target gene regions of the GFP positive hairy roots were amplified (Additional file 1: Fig. S2 and Table S6), and cloned into pClone007 simple vector (TsingKe, Nanjing, China). For each target region amplicon, 20 positive clones were selected for Sanger sequencing. The sequences were analyzed and aligned by using DNAman software (Lynnon Biosoft, USA).

\section{Supplementary information}

Supplementary information accompanies this paper at https://doi.org/10. 1186/s12870-020-02614-X.

\footnotetext{
Additional file 1 Fig. S1. DNA sequence homology of AhNFR genes in peanut. Fig. S2. Schematics of gene sequence, target sites and the regions of examined $P C R$ products of $A h N F R$ genes in transgenic hairy roots. (A) AhNFR1A2 and AhNFR1B2 genes, (B) AhNFR5A and AhNFR5B genes. NFR1AB1, NFR1AB2, NFR5AB1, NFR5AB2, and NFR5B are gRNAs. AhNFR1-EX-h, AhNFR5-EX-h, AhNFR5B-EX-h represent amplicons covering the target sites for examining the edited gene sequence. Fig. S3. PCR products of AhNFR1 gene in transgenic hairy roots. M: 1 kb plus marker; H1-H12: transgenic AhNFR1 samples; P1-P3: hairy roots with P201G empty vector; WT: Tifrunner peanut; -: negative control. Fig. S4. PCR products of AhNFR5 gene in transgenic hairy roots. M: DL2000 marker; F1-F10: transgenic AhNFR5 samples; P1-P3: hairy roots with P201G empty vector; WT: Tifrunner peanut; -: negative control. Fig. S5. PCR products of
} 
AhNFR5B gene in transgenic hairy roots. M: 1 kb plus marker; $5 \mathrm{~B} 1-5 \mathrm{~B} 10$ : transgenic AhNFR5B samples; P1-P3: hairy roots with P201G empty vector; WT: Tifrunner peanut; -: negative control. Table S1. Percentage of different CRISPR/Cas9-caused mutations at AhNFR1A2 and AhNFRIB2 DNA sequence sites of transgenic AhNFR1 hairy roots. Table S2. Percentage of different CRISPR/Cas9-caused mutations at AhNFR5A and AhNFR5B DNA sequence sites of transgenic AhNFR5 hairy roots. Table S3. The primers of AhNFR genes. Table S4. The primers of q-PCR of AhNFR genes. Table S5. Primers for constructing and examining CRISPR/Cas9:AhNFR vectors. Table S6. Primers for amplifying the target genes of transgenic AhNFR hairy roots.

Additional file 2. Original gel images presented in Fig. S3, Fig. S4, and Fig. S5.

\section{Abbreviations}

CDS: Coding DNA sequences; GFP: Green fluorescent protein; CRISPR/ Cas9: Clustered regularly interspaced short palindromic repeats/CRISPRassociated protein 9; HAl: Hours after inoculation; LYK: LysM receptor-like kinases; LysM: Lysin motif; NF: Nod factor; NFP: NF perception; NFR: NF receptor; q-PCR: Quantitative real time-PCR; RNAi: RNA interference; sgRNAs: Single guide RNAs

\section{Acknowledgements}

We appreciate Dr. Baozhu Guo at USDA-ARS at Tifton, GA for providing the seeds for the experiment.

\section{Authors' contributions}

JW conceived the research. JW and HS designed the experiments. HS, ZL and ZP conducted the experiments. HS analyzed the data and prepared the manuscript draft. JW, ZL and ZP revised the manuscript. All authors read and approved the final manuscript.

\section{Funding}

This study was funded by the Florida Peanut Producers Association, the University of Florida IFAS Early Career Scientists Award, and USDA National Institute of Food and Agriculture, Hatch Project 1011664. The funding agencies were not involved in the designing of the study and collection, analysis and interpretation of the data, and in the writing of the manuscript.

\section{Availability of data and materials}

The data generated or analyzed in this study are included in this article and supplementary information files. The sequencing data generated in this study were deposited in NCBI SRA database (BioProject: PRJNA655791, and SRA accession number: SRR12405032-SRR12405036). Other materials are available upon reasonable request to the corresponding author at wangjp@ufl. edu.

\section{Ethics approval and consent to participate}

Not applicable.

\section{Consent for publication}

Not applicable.

\section{Competing interests}

The authors declare that they have no competing interests.

\section{Author details}

IInstitute of Industrial Crops, Jiangsu Academy of Agricultural Sciences, Nanjing 210014, China. ${ }^{2}$ Agronomy Department, University of Florida, Gainesville, FL 32610, USA

Received: 5 August 2019 Accepted: 19 August 2020

Published online: 07 September 2020

\section{References}

1. Bertioli DJ, Cannon SB, Froenicke L, et al. The genome sequences of Arachis duranensis and Arachis ipaensis, the diploid ancestors of cultivated peanut. Nat Genet. 2016;48(4):438-46.

2. Bertioli DJ, Jenkins J, Clevenger J, et al. The genome sequence of segmental allotetraploid peanut Arachis hypogaea. Nat Genet. 2019;51:877-84.
3. Zhuang $\mathrm{W}$, Chen $\mathrm{H}$, Yang $\mathrm{M}$, et al. The genome of cultivated peanut provides insight into legume karyotypes, polyploid evolution and crop domestication. Nat Genet. 2019;51:865-76.

4. Tang G, Xu P, Ma W, Wang F, Liu Z, Wan S, Shan L. Seed-specific expression of AtLEC1 increased oil content and altered fatty acid composition in seeds of peanut (Arachis hypogaea L.). Front Plant Sci. 2018;9:260. https://doi.org/ 10.3389/fpls.2018.00260.

5. Das DR, Horvath B, Kundu A, Kalo P, DasGupta M. Functional conservation of CYCLOPS in crack entry legume Arachis hypogaea. Plant Sci. 2019;281:232-41.

6. Kundu A. DasGupta. Silencing of putative cytokinin receptor histidine kinase 1 inhibits both inception and differentiation of root nodules in Arachis hypogaea. Mol Plant-Microbe Interact. 2018;31(2):187-99.

7. Yin K, Gao C, Qiu JL. Progress and prospects in plant genome editing. Nat Plants. 2017;3:17107

8. Chen K, Wang Y, Zhang R, Zhang H, Gao C. CRISPR/Cas genome editing and precision plant breeding in agriculture. Annu Rev Plant Biol. 2019;70: 667-97.

9. Jaganathan D, Ramasamy K, Sellamuthu G, Jayabalan S, Venkataraman G. CRISPR for crop improvement: an update review. Front Plant Sci. 2018;9:985. https://doi.org/10.3389/fpls.2018.00985.

10. Munoz V, Ibanez F, Tordable M, Megias M, Fabra A. Role of reactive oxygen species generation and nod factors during the early symbiotic interaction between bradyrhizobia and peanut, a legume infected by crack entry. J Appl Microbiol. 2015;118(1):182-92.

11. Ibanez F, Wall L, Fabra A. Starting points in plant-bacteria nitrogen-fixing symbioses: intercellular invasion of the roots. J Exp Bot. 2017;68(8):1905-18.

12. Oldroyd GE, Murray JD, Poole PS, Downie JA. The rules of engagement in the legume-rhizobial symbiosis. Annu Rev Genet. 2011;45:119-44.

13. Wang J, Andersen SU, Ratet P. Molecular and cellular mechanisms of the legume-rhizobia symbiosis. Front Plant Sci. 2018;9:1839 doi: 10.3389/fpls. 2018.01839

14. Sharma V, Bhattacharyya S, Kumar R, Kumar A, Ibanez F, Wang J, Guo B, Sudini HK, Gopalakrishnan S, DasGupta M, Varshney RK, Pandey MK. Molecular basis of root nodule symbiosis between Bradyrhizobium and 'crack-entry' legume groundnut (Arachis hypogaea L.). Plants. 2020;9(2):276.

15. Karmakar K, Kundu A, Rizvi AZ, Dubois E, Severac D, Czernic P, Cartieaux F, Dasgupta M. Transcriptomic analysis with the progress of symbiosis in 'crack-entry' legume Arachis hypogaea highlights its contrast with 'infection thread' adapted legumes. Mol Plant-Microbe Interact. 2019;32(3):271-85.

16. Boogerd FC, Rossum DV. Nodulation of groundnut by Bradyrhizobium: a simple infection process by crack entry. FEMS Microbiol Rev. 1997;21:5-27.

17. Maku J, Wang L, Liu F, Liu L, Kelley K, Peng Z, Wang J. Involvement of root hair during rhizobial invasion in cultivated peanut (Arachis hypogaea L.). Am J Plant Sci. 2018:9(8):1646-59.

18. Tsikou D, Ramirez EE, Psarrakou IS, Wong JE, Jensen DB, Isono E, Radutoiu S, Papadopoulou KK. A Lotus japonicus E3 ligase interacts with the nod factor receptor 5 and positively regulates nodulation. BMC Plant Biol. 2018;18:217.

19. Madsen EB, Madsen LH, Radutoiu S, Olbryt M, Rakwalska M, Szczyglowski K, Sato S, Kaneko T, Tabata S, Sandal N, Stougaard J. A receptor kinase gene of the LysM type is involved in legume perception of rhizobial signals. Nature. 2003:425:637-40.

20. Radutoiu S, Madsen LH, Madsen EB, Felle HH, Umehara Y, Gronlund M, Sato S, Nakamura Y, Tabata S, Sandal N, Stougaard J. Plant recognition of symbiotic bacteria requires two LysM receptor-like kinases. Nature. 2003;425 585-92.

21. Indrasumunar A, Gresshoff PM. Duplicated nod-factor receptor 5 (NFR5) genes are mutated in soybean. Plant Signal Behav. 2010;5(5):535-6.

22. Indrasumunar A, Kereszt A, Searle I, Miyagi M, Li D, Nguyen CDT, Men A Carroll BJ, Gresshoff PM. (2010). Inactivation of duplicated nod factor receptor 5 (NFR5) genes in recessive loss-of-function non-nodulation mutants of allotetraploid soybean (Glycine max L. Merr.). Plant Cell Physiol. 2010:51(2):201-14.

23. Indrasumunar A, Searle I, Lin MH, Kereszt A, Men A, Carroll BJ, Gresshoff PM. Nodulation factor receptor kinase 1a controls nodule organ number in soybean (Glycine max L. Merr.). Plant J. 2011;65:39-50.

24. Limpens E, Franken C, Smit P, Willemse J, Bisseling T, Geurts R. Lys M domain receptor kinases regulating rhizobial nod factor-induced infection. Science. 2003:302:630-3.

25. Oldroyd GED. Speak, friend, and enter: signalling systems that promote benefcial symbiotic associations in plants. Nat Rev Microbiol. 2013:11. 252-63. 
26. Peng Z, Liu F, Wang L, Zhou H, Paudel D, Tan L, Maku J, Gallo M, Wang J. Transcriptome profiles reveal gene regulation of peanut (Arachis hypogaea L.) nodulation. Sci Rep. 2017;7:40066 doi: 10.1038/srep40066.

27. Ibanez F, Angelini J, Figueredo MS, Munoz V, Tonelli ML, Fabra A. Sequence and expression analysis of putative Arachis hypogaea (peanut) nod factor perception proteins. J Plant Res. 2015;128:709-18.

28. Lee WK, Jeong N, Indrasumunar A, Gresshoff PM, Jeong SC. Glycine max non-nodulation locus rj1: a recombinogenic region encompassing a SNP in a lysine motif receptor-like kinase (GmNFR1a). Theor Appl Genet. 2011;122: 875-84.

29. Madsen EB, Antolin-Llovera M, Grossmann C, Ye J, Vieweg S, Broghammer A, Krusell L, Radutoiu S, Jensen ON, Stougaard J, Parniske M. Autophosphorylation is essential for the in vivo function of the Lotus japonicus nod factor receptor 1 and receptor-mediated signalling in cooperation with nod factor receptor 5. Plant J. 2011;65:404-17.

30. Peng Z, Tan L, Lopez Y, Maku J, Liu F, Zhou H, Tseng YC, Yang X, Hsieh YF, Song J, Wang L, Tillman BL, Gallo M, Wang J. Morphological and genetic characterization of non-nodulating peanut recombinant inbred lines. Crop Sci. 2018;58:540-50.

31. Geurts R, Fedorova E, Bisseling T. Nod factor signaling genes and their function in the early stages of rhizobium infection. Curr Opin Plant Biol. 2005;8:346-52

32. Gough C, Jacquet C. Nod factor perception protein carries weight in biotic interactions. Trends Plant Sci. 2013;18(10):566-74

33. Li C, Unver T, Zhang B. A high-efficiency CRISPR/Cas9 system for targeted mutagenesis in Cotton (Gossypium hirsutum L.). Sci Rep. 2017;7:43902.

34. Jacobs TB, Lafayette PR, Schmitz RJ, Parrott WA. Targeted genome modifications in soybean with CRISPR/Cas9. BMC Biotechnol. 2015;15:16.

35. Zhou H, Liu B, Weeks DP, Spalding MH, Yang B. Large chromosomal deletions and heritable small genetic changes induced by CRISPR/Cas9 in rice. Nucleic Acids Res. 2014;42(17):10903-14.

36. Lowder LG, Zhang D, Baltes NJ, Paul JW, Tang X, Zheng X, Voytas DF, Hsieh TF, Zhang Y, Qi Y. A CRISPR/Cas 9 toolbox for multiplexed plant genome editing and transcriptional regulation. Plant Physiol. 2015;169:971-85.

37. Sinharoy S, Saha S, Chaudhury SR, DasGupta M. Transformed hairy roots of Arachis hypogea: a tool for studying root nodule symbiosis in a non-infection thread legume of the Aeschynomeneae tribe. Mol Plant-Microbe Interact. 2009:22:132-42.

38. Mehravar M, Shirazi A, Nazari M, Banan M. Mosaicism in CRISPR/Cas9-mediated genome editing. Dev Biol. 2019;445(2):156-62.

39. Smit P, Limpens E, Geurts R, Fedorova E, Dolgikh E, Gough C, Bisseling T. Medicago LYK3, an entry receptor in rhizobial nodulation factor signaling. Plant Physiol. 2007;145:183-91.

40. Radutoiu S, Madsen LH, Madsen EB, Jurkiewicz A, Fukai E, Quistgaard EMH, Albrektsen AS, James EK, Thirup S, Stougaard J. LysM domains mediate lipochitin-oligosaccharide recognition and NFR genes extend the symbiotic host range. EMBO J. 2007;26:3923-35.

41. Paudel D, Liu F, Wang L, Crook M, Maya S, Peng Z, Kelley K, Ane JM, Wang $J$ Isolation, characterization, and complete genome sequence of a Bradyrhizobium strain Lb8 from nodules of peanut utilizing crack entry infection. Front Microbiol. 2020;11:93.

42. Arnold K, Bordoli L, Kopp J, Schwede T. The SWISS MODEL workspace: a web-based environment for protein structure homology modeling. Bioinformatics. 2006;22(2):195-201.

43. Tamura K, Peterson D, Peterson N, Stecher G, Nei M, Kumar S. MEGA5: molecular evolutionary genetics analysis using maximum likelihood, evolutionary distance, and maximum parsimony methods. Mol Biol Evol. 2011;28:2731-9.

44. Luo M, Dang P, Bausher MG, Holbrook CC, Lee RD, Lynch RE, Guo BZ. Identification of transcripts involved in resistance responses to leaf spot disease caused by Cercosporidium personatum in peanut (Arachis hypogaea). Phytopathology. 2005;95:381-7

45. Livak KJ, Schmittgen TD. Analysis of relative gene expression data using real-time quantitative PCR and the $2^{-\Delta \Delta C T}$ method. Methods. 2001;25:402-8.

46. Liu H, Ding Y, Zhou Y, Jin W, Xie K, Chen L. CRISPR-P 2.0: an improved CRIS PR/Cas9 tool for genome editing in plants. Mol Plant. 2017;10(3):530-2.

47. Kereszt A, Li D, Indrasumunar A, Nguyen CD, Nontachasiyapoom S, Kinkema $M$, Gresshoff PM. Agrobacterium rhizogenes-mediated transformation of soybean to study root biology. Nat Protoc. 2007;2:948-52.

48. Rogers SO, Bendich AJ. In: Gelvin SB, editor. Extraction of DNA from plant tissues: Plant molecular biology manual, Springer; 1989. p. 73-83.

\section{Publisher's Note}

Springer Nature remains neutral with regard to jurisdictional claims in published maps and institutional affiliations.
Ready to submit your research? Choose BMC and benefit from:

- fast, convenient online submission

- thorough peer review by experienced researchers in your field

- rapid publication on acceptance

- support for research data, including large and complex data types

- gold Open Access which fosters wider collaboration and increased citations

- maximum visibility for your research: over $100 \mathrm{M}$ website views per year

At $\mathrm{BMC}$, research is always in progress.

Learn more biomedcentral.com/submissions 